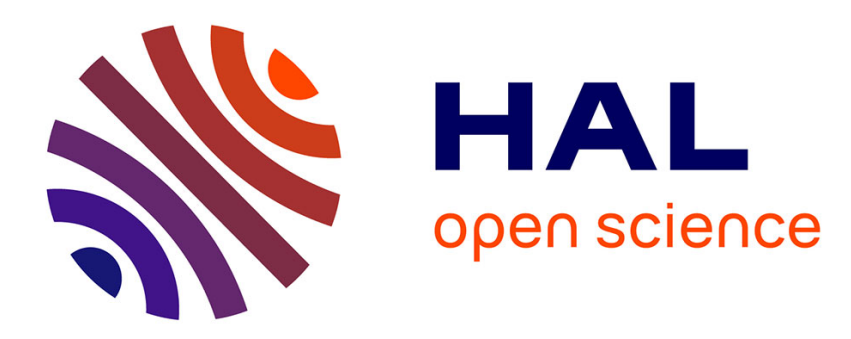

\title{
Action observation and execution: What is shared?
} Frédérique de Vignemont

\section{To cite this version:}

Frédérique de Vignemont. Action observation and execution: What is shared?. Social Neuroscience, 2008, pp.421-433. ijn_00352453

\section{HAL Id: ijn_00352453 \\ https://hal.science/ijn_00352453}

Submitted on 13 Jan 2009

HAL is a multi-disciplinary open access archive for the deposit and dissemination of scientific research documents, whether they are published or not. The documents may come from teaching and research institutions in France or abroad, or from public or private research centers.
L'archive ouverte pluridisciplinaire $\mathbf{H A L}$, est destinée au dépôt et à la diffusion de documents scientifiques de niveau recherche, publiés ou non, émanant des établissements d'enseignement et de recherche français ou étrangers, des laboratoires publics ou privés. 
This article was downloaded by: [de Vignemont, Frédérique]

On: 3 November 2008

Access details: Access Details: [subscription number 905025115]

Publisher Psychology Press

Informa Ltd Registered in England and Wales Registered Number: 1072954 Registered office: Mortimer House, 37-41 Mortimer Street, London W1T 3JH, UK

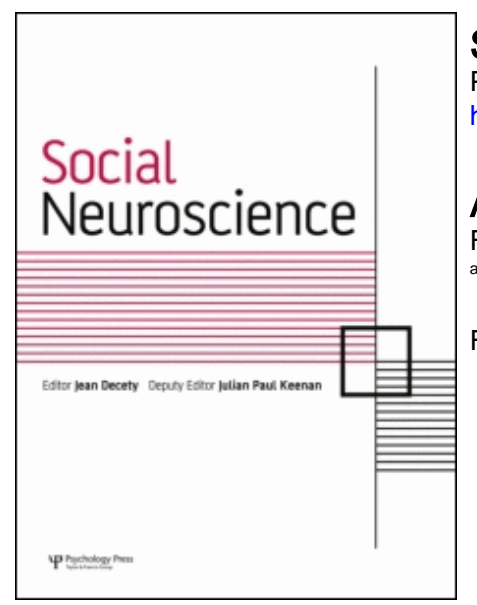

\section{Social Neuroscience}

Publication details, including instructions for authors and subscription information:

http://www.informaworld.com/smpp/title content=t741771143

\section{Action observation and execution: What is shared?}

\section{F. de Vignemont $\mathrm{a}$; P. Haggard ${ }^{\mathrm{b}}$}

${ }^{a}$ CNRS-EHESS-ENS, Paris, France ${ }^{b}$ University College London, London, UK

First Published on: 23 May 2008

To cite this Article de Vignemont, F. and Haggard, P.(2008)'Action observation and execution: What is shared?',Social Neuroscience, $3: 3,421-433$

To link to this Article: DOI: $10.1080 / 17470910802045109$

URL: http://dx.doi.org/10.1080/17470910802045109

\section{PLEASE SCROLL DOWN FOR ARTICLE}

Full terms and conditions of use: http://www.informaworld.com/terms-and-conditions-of-access.pdf

This article may be used for research, teaching and private study purposes. Any substantial or systematic reproduction, re-distribution, re-selling, loan or sub-licensing, systematic supply or distribution in any form to anyone is expressly forbidden.

The publisher does not give any warranty express or implied or make any representation that the contents will be complete or accurate or up to date. The accuracy of any instructions, formulae and drug doses

should be independently verified with primary sources. The publisher shall not be liable for any loss, actions, claims, proceedings, demand or costs or damages whatsoever or howsoever caused arising directly or indirectly in connection with or arising out of the use of this material. 


\title{
Action observation and execution: What is shared?
}

\author{
F. de Vignemont \\ CNRS-EHESS-ENS, Paris, France \\ P. Haggard \\ University College London, London, UK
}

\begin{abstract}
Performing an action and observing it activate the same internal representations of action. The representations are therefore shared between self and other (shared representations of action, SRA). But what exactly is shared? At what level within the hierarchical structure of the motor system do SRA occur? Understanding the content of SRA is important in order to decide what theoretical work SRA can perform. In this paper, we provide some conceptual clarification by raising three main questions: (i) are SRA semantic or pragmatic representations of action?; (ii) are SRA sensory or motor representations?; (iii) are SRA representations of the action as a global unit or as a set of elementary motor components? After outlining a model of the motor hierarchy, we conclude that the best candidate for SRA is intentions in action, defined as the motor plans of the dynamic sequence of movements. We shed new light on SRA by highlighting the causal efficacy of intentions in action. This in turn explains phenomena such as inhibition of imitation.
\end{abstract}

\section{INTRODUCTION}

In 1992, researchers in Parma reported the existence of neurons that fired both when a monkey was grasping a peanut and when it was watching the experimenter grasping it. They named them "mirror neurons" because they reflect other people's actions (di Pellegrino, Fadiga, Fogassi, Gallese, \& Rizzolatti, 1992; Gallese, Fadiga, Fogassi, \& Rizzolatti, 1996; Rizzolatti, Fadiga, Gallese, \& Fogassi, 1995). In humans, action observation and action execution activate overlapping brain areas including the supplementary motor area, the dorsal premotor cortex, the supramarginal gyrus, the superior parietal lobe and the Broca's area (Grezes \& Decety, 2001). It was therefore argued that the same internal representations of action is shared between self and other (shared representations of action, SRA).
By linking self and others within a unique representational framework, SRA have been considered to be at the core of intersubjectivity (Gallese, 2003), potentially playing a role in imitation (Iacoboni et al., 1999), empathy (Preston \& de Waal, 2002), mindreading (Gallese \& Goldman, 1998), and language (Rizzolatti \& Arbib, 1998). According to Ramachandran (2004), mirror neurons had even been a necessary condition for the so-called "big bang" of human evolution 40,000 years ago - a sudden explosion of human mental abilities and culture including even art and mathematics. SRA could indeed parsimoniously solve several problems raised by interpersonal relationships by enabling direct matching between self and others.

However, SRA might not provide such a universal answer, as shown by some recent criticisms both on the empirical and on the conceptual sides (Grèzes \& Decety, 2001) about

Correspondence should be addressed to: Frederique de Vignemont, Institut Jean-Nicod, CNRS-EHESS-ENS, 29 rue d'Ulm, 75005 Paris, France. E-mail: fvignemont@isc.cnrs.fr

(C) 2008 Psychology Press, an imprint of the Taylor \& Francis Group, an Informa business www.psypress.com/socialneuroscience 
the link with language; Saxe (2005) about the link with simulation theory; Jacob \& Jeannerod (2005) about the link with mindreading). After the excitement of the discovery of SRA and their possible consequences for social cognition, there is a need for clarifications and conceptual cautiousness. As a preliminary step, it is necessary to understand what is indeed shared between action execution and action observation. Only if we know in detail the content of SRA can we decide what work SRA can perform. In particular, we need to situate SRA within the architecture of action. Both cognitive and neural models identify many representational stages and processes which contribute to action execution (Jeannerod, 1997; Wolpert, Ghahramani, \& Jordan, 1995). At what level within the hierarchical structure of the motor system do SRA occur? The aim of this paper is to step back from speculation about the possible roles of SRA and to start at the beginning by asking: what is shared?

\section{DIFFERENT LEVELS OF ACTION REPRESENTATIONS}

The hypothesis of SRA can be articulated as follows:

1. Two tokens of the same type of action representation are activated in two individuals' brains.

2. The activation in one individual is triggered by the observation of the other individual acting.

Both claims raise questions, but most recent interest has focused on the latter claim. How is the observation of the performed movement related to the activation of SRA? Is the relationship direct or not (Csibra, 2007)? Does it result from an associative learning mechanism (Heyes and Bird, 2007)? In contrast, we will focus here on the former claim of the SRA hypothesis: what kind of action representation is instantiated both in the agent and in the observer?

SRA are defined relative to their context of activation (execution versus observation), but these two notions are too broad to be useful. According to Anscombe (1957), there is an almost infinite list of possible descriptions of the same action: I turn the tap clockwise, I open the tap, I get some water, I intend to drink. Similarly, at the computational level, the goal of the action is represented at different levels of complexity that are hierarchically organized (i.e. a set of motor commands, a series of intermediary movements, the final outcome) (Wolpert, Doya, \& Kowato, 2003). The contextual definition of SRA is not sufficient to define what level of action representation one has access to when observing someone else's movement. Exactly what information is shared? We need to take account of the complexity of the motor system to be able to specify what is common between action execution and action observation.

We begin by considering whether SRA could be localized to the upstream, intentional motor system. There are at least two kinds of intention (Pacherie, 2000; Searle, 1983). Prior intentions represent the goal of the action as a global unit (e.g. I intend to drink). They are too roughgrained to specify the movements that have to be performed. There may be several means to realize the same prior intention. The motor system needs to anchor the prior intention in a specific context and to determine the means that will be required to reach the goal, that is, the intention in action. Intentions in action represent the action as a dynamic sequence of specific movements (e.g. I intend to reach the tap and to turn it clockwise with the right hand). They initiate the action, guide it and monitor its effects. They correspond to the motor plan, prior to the dispatch of the final motor command to the muscles (Jeannerod, 1995). The intention in action therefore has a level of motor specificity that prior intentions lack. For this reason, intentions in action can be identified with the inverse model in computational frameworks. The inverse model has the role of computing the motor commands needed to achieve the desired state given the agent's current body state (Wolpert et al., 1995). The motor system also anticipates both the motor and the sensory consequences of the movement through two kinds of forward model (Frith, 2005; Wolpert et al., 1995). The forward dynamic model predicts what an action will be like given the specific body that executes the motor commands (e.g. how far the arm will stretch given its size). The output of the forward dynamic model is encoded in a motor format. It is involved in motor imagery and allows anticipatory control of movements. For example, we need to anticipate the changing gravitational forces when we move a heavy object up and down, and thus to alter the grip force. The forward output model predicts the sensory feedback (e.g. where the arm will be at the end of the 
movement). The output of the forward output model is encoded in a sensory format. The prediction of the sensory consequences of the movements attenuates the actual sensations caused by the movements (Blakemore, Wolpert, \& Frith, 1998). This is why one cannot tickle oneself. Finally, there is the actual sensory feedback resulting from the execution of the action. Controlling actions requires running the different stages in an open-loop fashion. We may however want to freeze the action system at a moment in time, and ask whether the individual representations one finds might or might not be shareable.

In summary, SRA may happen at different levels: prior intention, intention in action, motor command, predicted motor outcome, predicted sensory outcome, and sensory feedback. These possibilities are not mutually exclusive. However, most of the neuroscience literature about SRA does not distinguish clearly among these levels. The authors sometimes refer to intentions (Iacoboni et al., 2005), but without distinguishing prior intentions and intentions in action. Other authors suggest sharing of the predicted state resulting from the forward output model (Prinz, 2002). Still others include a further level of action representation, the semantic knowledge of what one does (Van Elk, Van Schie, \& Bekkering, 2007).

Figure 1 concerns processes and signals, and is based on information engineering. In contrast, most conceptual work on SRA describes representations in terms of their functions (see Figure 2). In order to situate these representations within process models, we suggest that three questions about SRA are essential.

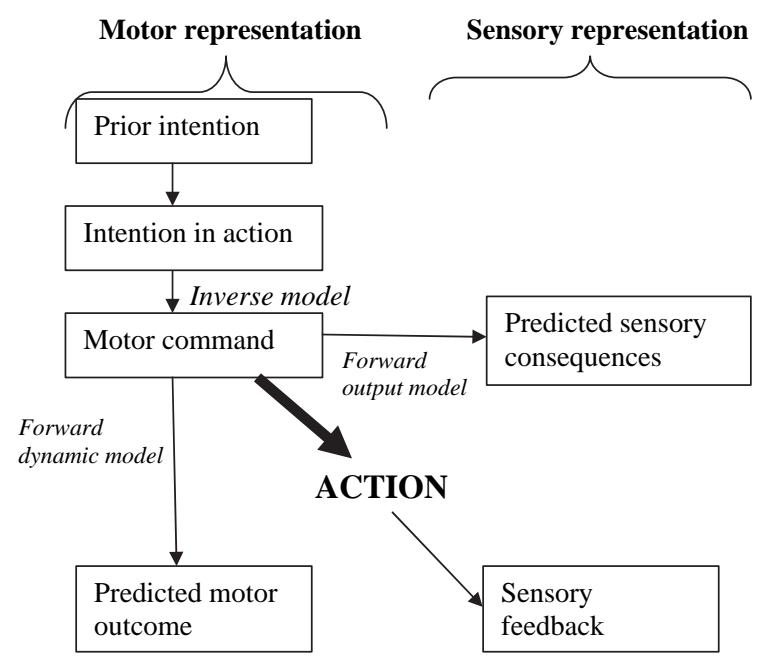

Figure 1. Hierarchical model of motor control.

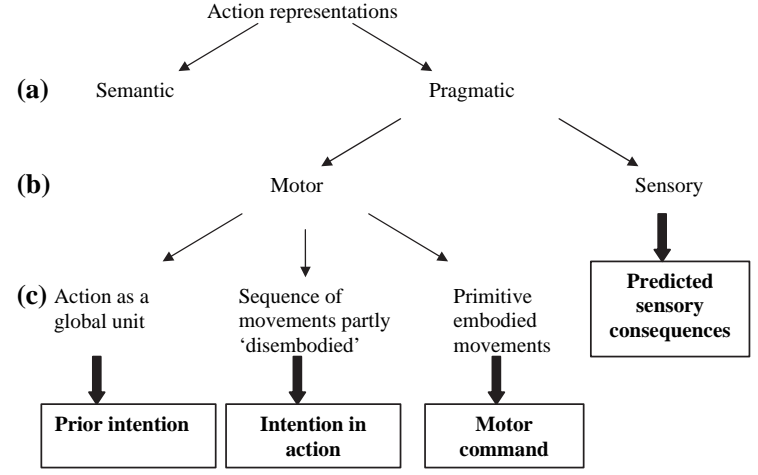

Figure 2. What is the content of SRA?

1. Are SRA semantic or pragmatic representations of action?

2. Are SRA sensory or motor representations?

3. Are SRA representations of the action as a global unit or as a dynamic sequence of elementary motor components?

Basic as they might seem, these questions are not easy to answer, as we will see. The past 15 years have seen an increasing number of studies about the relationship between perception and action, which sometimes provide conflicting results. This paper does not aim to review this vast amount of literature, but rather to suggest some answers based on a few key studies.

\section{SEMANTIC VERSUS PRAGMATIC}

According to the generality constraint (Evans, 1983), I master the concept 'to grasp' if I am able to use it to represent both that $I$ grasp a peanut/a glass of water and that John grasps a peanut/a glass of water ( $<x$ grasps $y>)$. Such definition of concepts meets the underlying requirement of SRA. And indeed, SRA have been said to encode a "motor vocabulary" shared between self and others (Rizzolatti et al., 1988). In favour of such a view, it was found that Broca's area contributes to action observation and imitation (Iacoboni et al., 1999; Koski et al., 2002). SRA would provide a conceptual understanding of action (Rizzolatti, Fogassi, \& Gallese, 2000). However, as pointed out by Goldman (2006), the same authors also describe SRA as a kind of "direct experiential understanding" of someone else's actions (Gallese, Keysers and Rizzolatti, 2004, p. 396; emphasis added). They emphasize that "Conceptual reasoning is not necessary for this understanding." There is an apparent contradiction 
here. On the one hand, the relationship between action observation and execution would be mediated by conceptual processes. On the other hand, it would be immediate, leading to a direct experience of someone else's action from a firstperson perspective as if one were moving. ${ }^{1}$

The best way to capture the difference between these two views may be to use the distinction between semantic and pragmatic representations of action, as defined by Jeannerod (1994). Semantic representations encode the properties of the observed actions to identify them, and to keep track of them. They are based on visual recognition expertise and they are linked to linguistic representations (e.g. action naming tasks), and to a wider semantic network of other concepts connected with the recognized action. This knowledge is from a third-person perspective. The observer does not put herself in the agent's shoes; she remains an external witness. In contrast, pragmatic representations represent actions from the first-person point of view of the agent in interaction with the world. They encode the properties of the motor system for optimization of action execution, as well as the properties of the object relevant for the interaction between the agent and the object. They allow the observer to reproduce the same movement through imitation.

This leads us to our first question. Are SRA semantic or pragmatic representations of actions? Like any semantic knowledge, action knowledge can be indifferently applied both to the self and to others. However, if the sharing were limited to conceptual recognition, there would be no particular interest in SRA. I would understand other people's actions in the same way that I understand the movements of the clouds in the sky: in both cases, I apply a semantic knowledge previously acquired. Alternatively, one may argue that what makes SRA special is that they go beyond this mere conceptual sharing. One would not share only the knowledge about the action; one would share the agent's inner perspective. SRA would then allow the observer to internalize someone else's actions as if she were the agent, and not just an external witness.

\footnotetext{
${ }^{1}$ Gallese \& Lakoff (2005) provide an embodied account of concepts, which would erase the contradiction. However, for various reasons, we prefer to maintain a distinction between the experiential nonconceptual level and the conceptual level. Nonetheless, we agree that the nonconceptual level can ground the conceptual level.
}

Recent behavioral results have shown the influence of semantic representations on action, suggesting that one could have semantically mediated SRA (Gentilucci \& Gangitano, 1998; Gentilucci, Benuzzi, Bertolani, Daprati, \& Gangitano, 2000; Glover \& Dixon, 2002; Glover, Rosenbaum, Graham, \& Dixon, 2004). For example, Gentilucci \& Gangitano (1998) found a priming effect of action words on movement kinematics. Subjects had to grasp two bars of the same size, one named 'small' and the other named 'large'. The grip aperture was influenced by the tag on the bar. More recently, Van Elk and coworkers have produced several results suggesting a role of conceptual representations of action in mirror phenomena, and thus supporting a semantic view (Van Elk et al., 2007; Lindemann, Stenneken, van Schie, \& Bekkering, 2006). Subjects grasped and used one of two objects (cup or magnifying glass) if the word subsequently presented was lexically valid (go) or withheld from moving if a nonword was presented (no-go). Two kinds of words were presented: either congruent or incongruent with the action to perform (e.g. mouth or eye). Subjects responded faster when the word was congruent. The authors showed an interaction effect between action preparation and word reading.

These interesting results underline the importance of our conceptual knowledge for actions. They show that action execution is sensitive not only to action observation, but also to action words. However, they do not show that the pathway between perception and action is always mediated by the semantic knowledge of acts. These results do not show that we are sensitive exclusively to conceptual representations of actions. Nor do they show that what is shared is only semantic knowledge. There might additionally be a direct pathway between observation and action, relying only on shared pragmatic representations of action. But how can these two putative representations be untangled?

The distinction between semantic and pragmatic representations of action raises a real difficulty for neuroscience. How can brain imagery studies or cell recording differentiate between pragmatic representations from a firstperson perspective and semantic representations from a third-person perspective? A recent study tackles this issue by using motor and visual expertise to differentiate between first-person and third-person perspective (Calvo-Merino, Grezes, Glaser, Passingham, \& Haggard, 2006). 
Ballet dancers, both male and female, watched short videos of ballet movements. The movements chosen were either performed exclusively by male dancers, performed exclusively by female dancers, or common to male and female. The underlying assumption was that dancers have visual familiarity for all the movements, but only motor familiarity for movements of their own gender. If there was nothing more to SRA than a mere semantic representation of dance, then there should not be any difference between the conditions. However, this was not the case: mirror system activity was greater when subjects watched movements specific to their own gender, for which they had acquired the appropriate motor representations. Questionnaire data and brain activity suggested that semantic knowledge of the different movement types, such as visual recognition and naming, did not differ between the groups. This study provides a conclusive argument in favor of the existence of pragmatic representations of action shared between self and others.

To sum up, although semantic representations can affect action execution, semantic representations do not suffice to account for all the data and pragmatic representations also seem to be involved. It remains however an open question whether semantic representations are necessary or not, although they are not sufficient. It has been proposed recently a dual-route model: the link between sensory and motor can be either direct (through associative learning mechanism for instance) or linguistically mediated (Heyes, 2001; Tessari and Rumiati, 2004). Similarly, the direct matching hypothesis assumes that we do not need semantic mediation (Gallese et al., 2004). On these views, SRA seem to involve sharing of a nonconceptual, nonsemantic, pragmatic form of representation from a first-person perspective based on the representations that agents have of executing actions.

\section{SENSORY VERSUS MOTOR}

We have shown that the relationship between action observation and action execution is not always mediated by semantic representations of action. There is, in addition, a direct link between perception and action, which does not require a conceptual translation from one to the other. Such direct matching is possible if and only if some levels in the perceptual process and in the motor process are commensurate. But what code is common to perception and action? Is it sensory: "actions are represented at the common meeting place in terms of their sensory or perceptual consequences" (Prinz, 2002, p. 173)? Or is it motor: "the perception-action mediation relies on motor representations that are already activated (or formed) during observation" (Decety and Grezes, 1999, p. 177)?

The content of SRA is shown in Figure 2; sensory versus motor sharing is depicted in Figure 3.

According to the sensory view, the observation of a kinematic pattern is directly matched with the anticipation of the sensory consequences of the action. The anticipatory image of the sensory feedback of actions is associated in a bidirectional way with the actions that lead to them (effect $\Leftrightarrow$ movement). Its activation thus in turn activates the motor representation of the corresponding action. The mechanism of SRA is sensory, but the indirect consequence is that two people have common motor representations. The sensory common coding view can explain a number of studies based on interference between execution and action observation. The interference arises because of the similarity between the sensory representations of the movement observed and the movement predicted.

In contrast, according to the motor view, action observation triggers a covert simulation of the motor program (Gallese, 2003; Jeannerod, 1994). A meta-analysis of brain imaging studies has shown an overlap of activations between execution, observation and mental simulation of action (Grèzes \& Decety, 2001). To put it another way, motor imagery is the conscious counterpart of SRA (Decety, 2002), and might be considered as

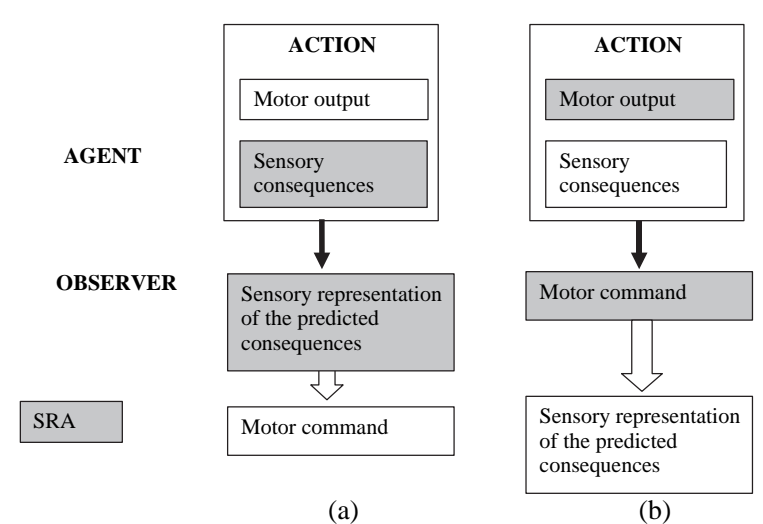

Figure 3. (a) Sensory sharing versus (b) motor sharing. 
the key for understanding SRA. ${ }^{2}$ However, the activation of the motor program in turn activates also the representation of the sensory consequences.

In addition, there may be several intermediate positions between a purely sensory view and a purely motor view (Hommel et al., 2001; Keysers \& Perrett, 2004). How might one dissociate sensory and motor components? Indeed, is it possible to do so? One possibility is to look at the neural network underlying SRA. It includes areas that are classically considered motor (e.g. ventral premotor cortex). This observation formed part of the original interest of SRA: perceptual tasks activate motor areas. However, both the sensory view and the motor view can account for such activation. In both views, both sensory and motor components of action representations are activated by action observation, whether it is directly or indirectly triggered by the representation of the sensory consequences. ${ }^{3}$ Consequently, it may be illusory to dissociate the sensory and the motor aspects. They are bound together into united "action files", which group together all the action-related features, both perceptual and motor (Hommel, 2004). What is shared would be the event file itself, and not its perceptual or its motor components.

However, it is possible to dissociate somatosensory and motor components of action mirroring in the cortex (Avenanti, Bolognini, Maravita, \& Aglioti, 2007). Those authors investigated observation of possible and impossible movements. Both classes of movement induce activations of mirror system areas thought to contain SRA (Costantini et al., 2005), and motor facilitation effects (Romani, Cesari, Urgesi, Facchini, \& Aglioti, 2005). However, Avenanti and coworkers showed that repetitive transcranial magnetic stimulation (rTMS) over ventral premotor cortex abolishes the motor facilitation effect during the observation of biologically possible movements, but not impossible movements. On the other hand, rTMS of primary somatosensory cortex

\footnotetext{
${ }^{2}$ However, as far as we know, there is no study that directly investigates the relationship between motor imagery and action observation.

${ }^{3}$ In order to untangle these two alternatives, one would need better neuroimaging tools that allow for a better temporal resolution (e.g. EEG and MEG) or an analysis of the effective connectivity (e.g. by dynamical causal modeling). This would permit one, for example, to determine what comes first: the representation of the sensory consequences or the motor representation.
}

decreases the motor facilitation effect during observation of biologically impossible, but not possible movements. This study thus dissociates two aspects of the motor facilitation effect. Only the first of these, which is specialized for biological action, and housed in ventral premotor cortex, can properly be considered to reflect the functions of the mirror system.

In addition, a few recent results argue in favour of sharing motor representations. Mirror neurons have been shown to fire even if the completion of the action is hidden behind a screen (Umiltà et al., 2001). To put it another way, one does not need to perceive the outcome of the action to activate SRA. This result is not sufficient in itself to argue against the sensory view. One might indeed still be able to make sensory predictions about the action output, although it has not been completed. However, a recent perceptual study has shown the influence of motor expertise on action observation independently of any visual expertise (Casile \& Giese, 2006). Blindfolded subjects learned to perform a novel coordinated movement based only on verbal and haptic feedback. The better they were at performing the movement, the better they were at recognizing it on a point-light display. The authors concluded that motor programs might be the dominating factor that explains the influence of motor training on movement recognition. ${ }^{4}$

Even more convincing evidence against the sensory view comes from results showing context dependence of SRA. If SRA represented the sensory consequences of the action, then their activation should be specific to the sensory consequences. They should not be directly affected by the context leading to the movement, since context does not modify the sensory consequences. However, Fogassi et al. (2005) showed that some mirror neurons responded differentially, depending on the kind of action in which the movement was embedded (e.g. grasping for eating versus grasping for placing). Although the sensory consequences were the same, the neural activation was not. The same type of results was found in humans (Iacoboni et al., 2005). The

\footnotetext{
${ }^{4}$ Once again, this study cannot exclude completely a possible role of the anticipation of the sensory consequences of the movement. Although subjects never had any visual feedback on the movement they learned, they might have predicted the visual consequences of their movement. Alternatively, there may be some intermodal translation from haptic to vision (Meltzoff, 1995).
} 
authors found differential activation of the right inferior frontal cortex relative to the context, the physical movement remaining the same. Consequently, the mere representation of the sensory outcome of the action cannot exhaust the content of SRA, as it is identical in both conditions. What matters here is the representation of the surrounding context.

In summary, (i) the lack of visual representation of the outcome does not prevent the activation of SRA (Casile \& Giese, 2006; Umiltà et al., 2001), and (ii) the observation of the same outcome can lead to different activation of SRA (Fogassi et al., 2005; Iacoboni et al., 2005). Since SRA are therefore unlikely to be sensory representations, they may instead be motor representations. Of course, motoric SRA might then activate sensory representations of the expected outcome indirectly, but our concern here is with direct sharing. Our suggestion of purely motoric SRA is consistent with Jeannerod's view that "an observer monitoring an action performed by someone else is never far from being also the agent of that action" (Jeannerod, 2003, p. 142).

\section{ACTION AS A GLOBAL UNIT VERSUS ACTION AS A DYNAMIC SEQUENCE OF ELEMENTARY MOTOR COMPONENTS}

We have seen that although both sensory and motor representations might be shared, the evidence favours sharing of motor representations over sensory ones. However, there are several possible levels of motor representations. Two factors must be considered to untangle the different levels within the motor system.

First, the degree of abstraction. At the computational level, hierarchical models of motor control such as HMOSAIC postulate the existence of at least three layers of motor representations: the goal, the sequence of movements, and the elements of movements (Jeannerod, 1995; Wolpert et al., 2003). The goal is the highest and the most abstract level (e.g. to get a drink of water). It activates the planning of the dynamic sequence of movements to perform in order to achieve the goal (e.g. to pour the water in the glass, to grasp the glass, and to bring it to the mouth). The precise kinematics of the sequence of movements is then computed taking account of the agent's body and the surrounding context (e.g. to stretch the arm for $20 \mathrm{~cm}$, to make a $5 \mathrm{~cm}$ grip aperture, to raise the arm with an elbow angle of $45^{\circ}$ ). We
TABLE 1

Three levels of motor representation

\begin{tabular}{|c|c|c|}
\hline & Abstraction & Embodiment \\
\hline Prior intention: the goal & +++ & + \\
\hline $\begin{array}{l}\text { Intention in action: dynamic } \\
\text { sequence of movements }\end{array}$ & ++ & ++ \\
\hline $\begin{array}{l}\text { Motor command: kinematics } \\
\text { of elements of movements }\end{array}$ & + & +++ \\
\hline
\end{tabular}

suggest that these three levels correspond to what we call prior intention, intention in action, and motor command (Table 1).

In parallel with the motor hierarchy, there is an embodiment hierarchy. Motor representations take account in more or less detail of bodily information necessary to perform the intended action. Bodily information can be either general (e.g. which limbs to move) or specific to the agent (e.g. the size of the limbs, joint angles or hand position) (Wolpert et al., 2003). In the latter case, the body state is not shared between the agent and the observer, who differ in their size and in their posture. SRA experiments can provide evidence about the level of embodiment at which sharing occurs, and this can therefore give empirical data about the level of abstraction.

Do SRA take into account precise bodily parameters? It has been shown that action observation leads to somatotopic activation of the premotor cortex (Buccino et al., 2001). In addition, the motor facilitation effect of action observation is muscle-specific (Fadiga, Fogassi, Pavesi, and Rizzolatti, 1995). Consequently, SRA encode bodily movements, and not merely abstract goals. However, SRA cannot represent the precise bodily kinematics in all its details, as shown by several experimental results. Csibra (2007) notes that only $19-41 \%$ of mirror neurons are classified as 'strictly congruent' (di Pellegrino et al., 1992; Ferrari, Gallese, Rizzolatti, \& Fogassi, 2003; Gallese et al., 1996; Gallese, Fogassi, Fadiga, \& Rizzolatti, 2002). Strict means that they fire only for observed actions of exactly the same type (e.g. not just grasping, but grasping with a particular hand configuration). The majority of mirror neurons fire when the observed action is "broadly congruent": they can respond to movements as different as grasping with the mouth and grasping with the hand (Gallese et al. 1996). What matters is the motor repertoire, not the individual body that performs the actions (Calvo-Merino et al., 2006). Somatotopic activation is indeed found even if the movement is 
performed by nonconspecifics such as monkeys or dogs (Buccino et al., 2004), or robots (Gazzola et al., 2007; Press, Bird, Flach, \& Heyes, 2005). What matters is that the observer can perform a functionally equivalent movement.

Furthermore, as we have seen, SRA are activated by the observation of biomechanically impossible movements (Avenanti et al., 2007; Costantini et al., 2005; Romani et al., 2005). It should be noted, however, that these so-called impossible movements are rather the exaggeration of physiologically possible movements, and thus share a number of features with them. Activation of SRA by biomechanically impossible stimuli may thus arise because specific bodily detail is lost when SRA match actions across bodies. Along the same lines, it was shown that two aplasic individuals born without hands activated regions of the mirror system involved in mouth and foot execution when observing hand movements (Gazzola, Rizzolatti, Wicker, \& Keysers, 2007). In contrast with Buccino et al. (2001, 2004), the activation was not somatotopic. To put it another way, SRA can and do abstract actions despite intersubjective differences, even when these differences are extreme.

A last argument against fully embodied SRA comes from the mirror neurons literature, and points towards the same conclusion as Gazzola et al. (2007). Some mirror neurons responded to the observation of tool-using actions (e.g. grasping food with a stick), although the monkeys themselves were unable to perform these actions (e.g. they grasped the food with their hand) (Ferrari, Rozzi, \& Fogassi, 2005). In this case, the kinematics of the two actions differs in important respects. For example, the direction and speed of motion, the angles between the joints, etc. cannot be shared in such cases.

To sum up, we consider that SRA do not represent movements in all their bodily parameters. SRA match not only the observed action to an executable action, but also someone else's body to one's own body. SRA may (Buccino et al., 2001) or may not (Ferrari et al., 2005; Gazzola et al., 2007) match spatial anatomical detail across bodies. However, they clearly cannot match dynamic information about muscular forces across bodies, since they are activated by observation of nonconspecifics' actions (Buccino et al., 2004). This is not so surprising given the fact that the agent's body almost always differs from the observer's body (e.g. in length and strength of the limbs). We know that children can imitate adults although their bodies differ completely. What they extract from the observed movements is the sequence of movements, not the way this sequence is implemented in the agent's particular body. And what they reproduce is not the precise kinematics, but the sequence of movements (e.g. to reach a target like the adult, they stretch their arm more than the adult). In fact, having access to such a level of bodily details would be useless as they are of no help if one wants to reproduce the movement, overtly or covertly.

Does this mean, however, that SRA represent disembodied abstract goals (Gazzola et al., 2007)? It does not seem so. Mirror activations are somatotopically organized. SRA represent the bodily sequence of movements that best corresponds in the observer's motor repertoire. If the observed effector is not available to the agent (e.g., the hand for the aplasic patients and the stick for the monkeys), then the motor system selects another effector able to perform the observed movement. However, by default, it is the same effector that is activated. One may even speculate that if the aplasic patients had phantom hands, one would find mirror activation in the region involved in hand movements. It was shown indeed that there are differences in action observation in aplasic patients with and without phantom limbs (Funk, Shiffrar, \& Brugger, 2005). They found that an aplasic individual with a phantom hand showed kinesthetically modulated perceptions of apparent hand motion, similar to controls, while an aplasic without a phantom did not. Thus, when the hand representation is present in the cortex, it appears to mediate action observation.

Let us now consider the level of abstraction of SRA. The classical view of mirror neurons has emphasized the congruence between the perceptual and the motor properties of the action: a neuron that is tuned for execution of a specific motor action shows visual selectivity for observing the same action (Gallese, 2003). Action understanding through SRA would be based on a one-to-one matching. Mirror neurons were said to be a replicative mechanism, which directly duplicates in a motor code the perceptual properties of actions. Recent evidence, however, has argued against such replicative mechanisms (for review, see Csibra (2007) and Jacob (2008)). On this view, SRA are far from being a faithful reproduction of what is observed. There is no 
one-to-one matching. But how far up should we go in the level of abstraction?

Rizzolatti, Fadiga, Fogassi, \& Gallese (2002) make the distinction between low-level and highlevel resonance mechanisms. The former encodes the specific movements; the latter encodes the global goal-directed action itself. The authors suggest that mirror neurons involve high-level intentional resonance, as suggested by Fogassi et al. (2005) and Iacoboni et al. (2005). ${ }^{5}$ This would seem to exclude the possibility of SRA operating at the most specific motor level, but it does not disentangle between intention in action and prior intention. Prior intentions differ from intentions in action in that they can be achieved by different means, whereas intentions in action specify in more detail the selected mean. To argue that SRA detect prior intentions, one would need to show similar brain activations when the displayed movements are completely different, although the global goal remains the same. As far as we know, this is not the case. In addition, access to the prior intention based on the observation of the movements only is difficult or impossible (Jacob \& Jeannerod, 2005).

We described at the beginning of this section three levels of action representations: the prior intention, the intention in action, and the motor command. These levels should not viewed as a conceptual tree-like structure where one can derive the most abstract level from the most concrete level (e.g. a human is a mammal). In the case of action, this sort of derivation (e.g. grasping is for eating) is not possible, because many possible prior intentions can correspond to a single specific movement (Jacob \& Jeannerod, 2005). A movement may be made for any of a number of purposes (Anscombe, 1957). It is thus difficult to directly "read" the prior intention from someone else's behavior, which remains ambiguous without further information.

SRA, by definition, begin with the observation of an action. The raw information is therefore a dynamic sequence of specific movements. We suggest that the motor system can abstract from

\footnotetext{
${ }^{5}$ For instance, Fogassi et al. (2005) assumed that the content of the intention detected by the monkey is something like "to eat", while it could be as well described as "to place in the mouth". It would be interesting to know what would happen if the monkey had to place either something eatable or something non-eatable in the mouth (hoping that everything is not eatable by monkeys). Then there would really be a similarity of intention in action with a difference of prior intentions.
}

the specific bodily parameters of the agent's movement to represent the underlying intention in action. But to go as far as the prior intention, one would need to abstract beyond the intention in action to a global goal. We agree with Jacob and Jeannerod that such abstraction is not possible based only on motor information. Therefore, one cannot have access to the prior intention based on the observation of the movements only.

We will illustrate our point here by using the key example of imitation. We define imitation as the reproduction of the goal of someone else's action. We assume that SRA contribute to imitation, not least because of their role in understanding action goals. There is currently considerable debate about the true nature and cognitive significance of imitation, but we will remain neutral within this debate (Rizzolatti et al., 2002; Wohlschläger \& Bekkering, 2002; Brass \& Heyes, 2005). We claim that sharing intentions in action is a minimal prerequisite of imitation. Imitation thus requires being sensitive to the dynamic sequence of movements that constitutes the action. In the absence of a common intention in action, imitation would be merely a kind of emulation or mimicry, a reproduction of the motor outcome by the observer's own means. Does imitation also require the understanding of prior intentions? In some cases, there might be no prior intention, as for meaningless gestures, yet one is still able to imitate them. However, when there is a prior intention, is it also shared?

Meltzoff (1995) claims that children as young as 18 months are able to "read" the underlying prior intention (i.e. grasping the stick) from the observation of the attempted but failed version of the action (the demonstrator's hand slipping several times). They did perform the target action correctly, even though they had only observed the failed movement. Interestingly, Meltzoff's study was conducted in a way that made the goal meaningful (grasping a stick by the two ends), while the failed movement observed by the children was meaningless (clumsy slipping movements). Melzoff claimed that they understood the demonstrator's prior intention. However, one could also suggest that they detected the affordances provided by the stick (e.g. meaningful actions that one can perform with a stick) and reproduced the action most similar to the observed movement, independently of the demonstrator's prior intention. It would be easy to check this interpretation experimentally. If the children 
read the prior intention from the movements observed, then they should be able to do so whether the act is meaningful or meaningless. For instance, they should be able to detect the demonstrator's prior intention to have his hand slipping and missing the stick end. But one would be very surprised if they could do so based on the observed movements. The problem with this study is that it confuses two different notions: meaningful and intentional.

We suggest that intentions in action already represent a dynamic sequence of movements as meaningful or meaningless and that we do not need to go as far as the prior intention to grasp this dimension. However, it is important to understand here that the fact that imitation requires a shared intention in action does not imply that imitation has to be to a perfect slavish copy of a set of movements independently of the global intention. The intention in action should not be confused with the motor command. It is more articulated, linking the set of movements into meaningful sequences when possible.

A further characteristic of imitation sheds new light on SRA. Imitation is a prepotent response tendency, which needs to be inhibited. Subjects make more errors and are slower to perform a movement when they watch an incongruent movement (Brass, Bekkering, Wohlschäger, \& Prinz, 2000). For instance, subjects move their index finger while they see the little finger moving. The observation of the little finger movement induces the subjects to do the same and they need to inhibit this tendency in order to perform the task. However, some patients with frontal lesions are no longer able to inhibit and compulsively imitate others (Lhermitte, 1983; Brass, Derrfuss, Matthes-von Cramon, \& von Cramon, 2003). Consequently, unless inhibited, the activation of the SRA during observation automatically leads to the execution of the corresponding action. It needs to be inhibited if the agent intends to perform another movement, or no movement at all.

In contrast with the inhibition mechanisms involved in non-imitative situations such as the Stroop task, the inhibition of imitation activates the anterior fronto-median cortex and the temporal-parietal junction (Brass, Derrfuss, \& von Cramon, 2005). Both areas are known to be involved in the sense of agency and in perspective-taking. Brass and colleagues (2005) claim that the distinction between internally generated and externally triggered motor representations plays a key role to prevent us from imitating someone else's movements. To put it another way, my brain incorporates a specific process to ensure that I do not imitate your movements. This process is adaptive and appropriate because your movements are yours, and do not match my own prior intentions.

One consequence of the phenomenon of inhibition of imitation is that SRA are causally efficient: they can play a significant role in action generation. We have argued that the main causal role of SRA is in supporting imitation of goaldirected action. Indeed, according to Searle (1983), both kinds of intention play a causal role: the prior intention causes the intention in action, which in turn causes bodily movements. Neuroscience has challenged the view that conscious prior intentions do actually play a causal role (Libet, 1985), but these results have no relevance for unconscious intentions in action. Causal efficacy would even be part of the content of intentions in action, which are "causally selfreferential" (Searle, 1983, p. 93). It is part of the content of an intention in action that this intention in action causes certain bodily movements (see Pacherie (2000) for discussion). If SRA do represent intentions in action, then, they include causal efficacy as well as the causally self-referential component.

SRA do indeed contribute to the observers themselves generating the action they observe, at least in imitation contexts. They correspond to the level in the motor hierarchy where action observation interacts with action execution, as shown for instance by interference effects and imitation inhibition effects. Observing someone else moving automatically activates the intention in action associated with this movement. This in turn automatically induces the fulfillment of this intention by virtue of the causal efficacy of the intention, unless it is inhibited. Such inhibition would in fact be the default state, and might be released only when the agent has the corresponding prior intention. Thus, an important part of higher motor cognition would be a tonic inhibition to keep SRA at bay, and to prevent our behavior being captured by others during social interaction. This inhibition is imposed by topdown influence outside the SRA system itself. Simulating an observed action is so close to doing it that a level of inhibition is required. However, it is interesting to note that in Brass's studies, subjects had the prior intention to move. What was affected by the observation of the incongru- 
ent movement was the selection of the performed movement (e.g. which index finger I move), not the decision to perform an action.

To sum up, SRA must represent (i) bodily movements, independently of the agent's or the observer's specific bodily parameters to allow transfer across individuals in imitation, (ii) the intermediate level of the planning of the dynamic sequence of movements. We consider therefore that intentions in action are a good candidate for SRA. Although the mirror neuron community has always considered SRA to be more about action understanding than about imitation, we think that this is not incompatible with our view. We are defining imitation not as slavish mimicry, but as reproducing a movement with some representation of the immediate goal, and that requires understanding what the observed sequence of movement is.

\section{CONCLUSION}

We have seen that SRA are causally efficient, in the sense that they tend to make me imitate. Consequently, they must be representations within the motor system, rather than just a conceptual label that I apply to your action in the same way I think about all other moving objects in the world. SRA must therefore involve intentional representations of action prior to the dispatch of a motor command. One should not, however, go too far up in the motor hierarchy. SRA must occur at a level indeterminate enough to apply to movements performed by different bodies, but also determinate enough to be extracted from the mere observation of movements. Intentions in action, defined as the planning of the dynamic sequence of elementary movements that causally triggers the motor command, appear then to be the best candidate for SRA.

Manuscript accepted 11 March 2008 First published online 23 May 2008

\section{REFERENCES}

Anscombe, G. E. M. (1957). Intention. London: Harvard University Press.

Avenanti, A., Bolognini, N., Maravita, A., \& Aglioti, S. M. (2007). Somatic and motor components of action simulation. Current Biology, 17(24), 2129-2135.
Blakemore, S. J., Wolpert, D. M., \& Frith, C. D. (1998). Central cancellation of self-produced tickle sensation. Nature Neuroscience, 1, 635-640.

Brass, M., Bekkering, H., Wohlschläger, A., \& Prinz, W. (2000). Compatibility between observed and executed finger movements: Comparing symbolic, spatial, and imitative cues. Brain and Cognition, 44(2), 124-143.

Brass, M., Derrfuss, J., Matthes-von Cramon, G., \& von Cramon, D. Y. (2003). Imitative response tendencies in patients with frontal brain lesions. Neuropsychology, 17(2), 265-271.

Brass, M., Derrfuss, J., \& von Cramon, D. Y. (2005). The inhibition of imitative and overlearned responses: A functional double dissociation. Neuropsychologia, 43(1), 89-98.

Brass, M., \& Heyes, C. (2005). Imitation: Is cognitive neuroscience solving the correspondence problem? Trends in Cognitive Sciences, 9, 489-495.

Buccino, G., Binkofski, F., Fink, G. R., Fadiga, L., Fogassi, L., Gallese, V., Seitz, R. J., Zilles, K., Rizzolatti, G. and Freund, H.-J. (2001). Action observation activates premotor and parietal areas in a somatotopic manner: An fMRI study. European Journal of Neuroscience, 13, 400-404.

Buccino, G., Lui, F., Canessa, N., Patteri, I., Lagravinese, G., Benuzzi, F., Porro, C. A., \& Rizzolatti, G. (2004). Neural circuits involved in the recognition of actions performed by nonconspecifics: An FMRI study. Journal of Cognitive Neuroscience, 16(1), 114126.

Calvo-Merino, B., Grezes, J., Glaser, D. E., Passingham, R. E., \& Haggard, P. (2006). Seeing or doing? Influence of visual and motor familiarity in action observation. Current Biology, 16(19), 1905-1910.

Casile, A., \& Giese, M. A. (2006). Nonvisual motor training influences biological motion perception. Current Biology, 16(1), 69-74.

Costantini, M., Galati, G., Ferretti, A., Caulo, M., Tartaro, A., Romani, G. L., \& Aglioti, S. M. (2005). Neural systems underlying observation of humanly impossible movements: An fMRI study. Cerebral Cortex, 15, 1761-1767.

Csibra, G. (2007). Action mirroring and action interpretation: An alternative account. In P. Haggard, Y. Rosetti, \& M. Kawato (Eds.), Sensorimotor foundations of higher cognition. Attention and performance XXII. Oxford, UK: Oxford University Press.

Decety, J. (2002). Is there such a thing as functional equivalence between imagined, observed and executed action? In A. N Meltzoff and W. Prinz (Eds.), The imitative mind. Cambridge, UK: Cambridge University Press.

Decety, J., \& Grezes, J. (1999). Neural mechanisms subserving the perception of human actions. Trends in Cognitive Science, 3(5), 172-178.

Di Pellegrino, G., Fadiga, L., Fogassi, L., Gallese, V., \& Rizzolatti, G. (1992). Understanding motor events: a neurophysiological study. Experimental Brain Research, 91, 176-180.

Evans, G. (1983). The Varieties of Reference. Oxford, UK: Oxford University Press.

Fadiga, L., Fogassi, L., Pavesi, G., \& Rizzolatti, G. (1995). Motor facilitation during action observation: 
A magnetic stimulation study. Journal of Neurophysiology, 73, 2608-2611.

Ferrari, P. F., Gallese, V., Rizzolatti, G., \& Fogassi, L. (2003). Mirror neurons responding to the observation of ingestive and communicative mouth actions in the monkey ventral premotor cortex. European Journal of Neuroscience, 17, 1703-1714.

Ferrari, P. F., Rozzi, S., \& Fogassi, L. (2005). Mirror neurons responding to observation of actions made with tools in monkey ventral premotor cortex. Journal of Cognitive Neuroscience, 17, 212-226.

Fogassi, L., Ferrari, P. F., Gesierich, B., Rozzi, S., Chersi, F., \& Rizzolatti, G. (2005). Parietal lobe: From action organisation to intention understanding. Science, 308, 662-667.

Frith, C. D. (2005). The self in action: Lessons from delusions of control. Consciousness and Cognition, 14(4), 752-770.

Funk, M., Shiffrar, M., \& Brugger, P. (2005). Hand movement observation by individuals born without hands: Phantom limb experience constrains visual limb perception. Experimental Brain Research, 164(3), 341-346.

Gallese, V. (2003). The manifold nature of interpersonal relations: The quest for a common mechanism. In C. Frith \& D. Wolpert (Eds.), The neuroscience of social interaction. Oxford, UK: Oxford University Press.

Gallese, V., \& Lakoll, G. (2005). The brain's concepts: The role of the sensory-motor system in reason and language. Cognitive Neuropsychology, 22, 455-479.

Gallese, V., Fadiga, L., Fogassi, L., \& Rizzolatti, G. (1996). Action recognition in the premotor cortex. Brain, 119, 593-609.

Gallese, V., Fogassi, L., Fadiga, L., and Rizzolatti, G. (2002). Action representation and the inferior parietal lobule. In W. Prinz and B. Hommel (Eds.), Attention and performance XIX. Common mechanisms in perception and action. Oxford, UK: Oxford University Press.

Gallese, V. and Goldman, A.I. (1998). Mirror neurons and the simulation theory of mindreading. Trends in Cognitive Sciences, 2(12), 493-501.

Gallese, V., Keysers, C., and Rizzolatti, G. (2004). A unifying view of the basis of social cognition. Trends in Cognitive Sciences, 8(9), 396-403.

Gazzola, V., Rizzolatti, G., Wicker, B., \& Keysers, C. (2007). The anthropomorphic brain: The mirror neuron system responds to human and robotic actions. NeuroImage, 35(4), 1674-1684.

Gazzola, V., van der Worp, H., Mulder, T., Wicker, B., Rizzolatti, G., \& Keysers, C. (2007). Aplasics born without hands mirror the goal of hand actions with their feet. Current Biology, 17(14), 1235-1240.

Gentilucci, M., \& Gangitano, M. (1998). Influence of automatic word reading on motor control. European Journal of Neuroscience, 10(2), 752-756.

Gentilucci, M., Benuzzi, F., Bertolani, L., Daprati, E., \& Gangitano, M. (2000). Language and motor control. Experimental Brain Research, 133(4), 468490.

Glover, S., \& Dixon, P. (2002). Semantics affect the planning but not control of grasping. Experimental Brain Research, 146(3), 383-387.
Glover, S., Rosenbaum, D. A., Graham, J., \& Dixon, P. (2004). Grasping the meaning of words. Experimental Brain Research, 154(1),103-108.

Goldman, A. I. (2006). Simulating Minds: The Philosophy, Psychology and Neuroscience of Mindreading. Oxford, UK: Oxford University Press.

Grèzes, J., \& Decety, J. (2001). Functional anatomy of execution, mental simulation, observation, and verb generation of actions: A meta-analysis. Human Brain Mapping, 12(1), 1-19.

Heyes, C. (2001). Causes and consequences of imitation. Trends in Cognitive Science, 5, 253-261.

Heyes, C. M., \& Bird, G. (2007) Mirroring, association and the correspondence problem. In P. Haggard, Y. Rossetti, \& M. Kawato (Eds.), Sensorimotor foundations of higher cognition, attention \& performance $X X$. Oxford, UK: Oxford University Press.

Hommel, B. (2004). Event files: Feature binding in and across perception and action. Trends in Cognitive Science 8(11), 494-500.

Hommel, B., Musseler, J., Aschersleben, G., \& Prinz, W. (2001). The Theory of Event Coding (TEC): A framework for perception and action planning. Behavioral and Brain Sciences, 24(5), 849-878.

Iacoboni, M., Molnar-Szakacs, I., Gallese, V., Buccino, G., Mazziotta, J.C., and Rizzolatti, G. (2005). Grasping the intentions of others with one's own mirror neuron system. PLoS Biology, 3(3), 529-535.

Iacoboni, M., Woods, R. P., Brass, M., Bekkering, H., Mazziotta, J. C., \& Rizzolatti, G. (1999). Cortical mechanisms of human imitation. Science, 286, 25262528.

Jacob, P. (2008). What do mirror neurons contribute to human social cognition? Mind \& Language, 23(2), 190-223.

Jacob, P. and Jeannerod, M. (2005). The motor theory of social cognition: A critique. Trends in Cognitive Sciences, 9(1), 21-25.

Jeannerod, M. (1994). The representing brain. Neural correlates of motor intention and imagery. Behavioral and Brain Sciences, 17, 187-245.

Jeannerod, M. (1995). Mental imagery in the motor context. Neuropsychologia, 33(11), 1419-1432.

Jeannerod, M. (1997). The cognitive neuroscience of action. Oxford, UK: Blackwell.

Jeannerod, M. (1999). The 25th Bartlett Lecture. To act or not to act: perspectives on the representation of actions. Quarterly Journal of Experimental Psychology, 52(1), 1-29.

Jeannerod, M. (2003). Consciousness of action and selfconsciousness: A cognitive neuroscience approach. In J. Roessler \& N. Eilan (Eds.), Agency and selfawareness: Issues in philosophy and psychology. Oxford, UK: Oxford University Press.

Keysers, C., \& Perrett, D. I. (2004). Demystifying social cognition: A Hebbian perspective. Trends in Cognitive Science, 8(11), 501-507.

Koski, L., Wohlschlager, A., Bekkering, H., Woods, R. P., Dubeau, M. C., Mazziotta, J. C., \& Iacoboni, M. (2002). Modulation of motor and premotor activity during imitation of target-directed actions. Cerebral Cortex, 12(8), 847-855. 
Lhermitte, F. (1983). Utilization behaviour and its relation to the lesion of the frontal lobe. Brain, 106, 237-255.

Libet, B. (1985). Unconscious cerebral initiative and the role of conscious will in voluntary action. Behavioral and Brain Sciences, 8, 529-566.

Lindemann, O., Stenneken, P., van Schie, H. T., Bekkering, H. (2006). Semantic activation in action planning. Journal of Experimental Psychology: Human Perception and Performance, 32(3), 633-643.

Meltzoff, A. N. (1995). Understanding intentions of others: Reenactment of intended acts by 18 monthsold children. Developmental Psychology, 31, 838850.

Pacherie, E. (2000). The content of intentions. Mind and Language, 15(4), 400-432.

Press, C., Bird, G., Flach, R., \& Heyes, C. (2005). Robotic movement elicits automatic imitation. Cognitive Brain Research, 25(3), 632-640.

Preston, S. D. and de Waal, F. B. M. (2002). Empathy: Its ultimate and proximate bases. Behavioral and Brain Sciences, 25, 1-20.

Prinz, W. (2002). Experimental approaches to imitation. In A. N Meltzoff \& W. Prinz (Eds.), The imitative mind. Cambridge, UK: Cambridge University Press.

Ramachandran, V. S. (2004). Mirror neurons and imitation learning as the driving force behind "the great leap forward" in human evolution. Edge Foundation. Retrieved March 18, 2008 from www. edge.org/3rd_culture/ramachandran/ramachandran_ p1.html

Rizzolatti, G., \& Arbib, M. A. (1998). Language within our grasp. Trends in Neuroscience, 21(5),188-194.

Rizzolatti, G., Camarda, R., Fogassi, M., Gentilucci, M., Luppino, G., \& Matelli, M. (1988). Functional organization of inferior area 6 in the macaque monkey: II. Area F5 and the control of distal movements. Experimental Brain Research, 71, 491507.

Rizzolatti, G., Fadiga, L., Fogassi, L., \& Gallese, V. (2002). From mirror neurons to imitation: Facts and speculations. In A. N Meltzoff and W. Prinz (Eds.), The imitative mind. Cambridge, UK: Cambridge University Press.
Rizzolatti, G., Fadiga, L., Gallese, V., \& Fogassi, L. (1995). Premotor cortex and the recognition of motor actions. Cognitive Brain Research, 3, 131-141.

Rizzolatti, G., Fogassi, L., \& Gallese, V. (2000). Cortical mechanisms subserving object grasping and action recognition: A new view of the cortical motor functions. In M. Gazzaniga (Ed.), The new cognitive neuroscience. Cambridge, MA: MIT Press.

Romani, M., Cesari, P., Urgesi, C., Facchini, S., \& Aglioti, S. M. (2005). Motor facilitation of the human cortico-spinal system during observation of bio-mechanically impossible movements. NeuroImage, 26(3), 755-763.

Saxe, R. (2005). Against simulation: The argument from error. Trends in Cognitive Sciences, 9(4), 174 179.

Searle, J. (1983). Intentionality: An essay in the philosophy of mind. Cambridge, UK: Cambridge University Press.

Tessari, A., \& Rumiati, R. I. (2004). The strategic control of multiple routes in imitation of actions. Journal of Experimental Psychology: Human Perception and Performance, 30, 1107-1116.

Umiltà, M. A., Kohler, E., Gallese, V., Fogassi, L., Fadiga, L., Keysers, C. \& Rizzolatti, G. (2001). 'I know what you are doing': a neurophysiological study. Neuron, 32, 91-101.

Van Elk, M., van Schie, H. T., \& Bekkering, H. (2007). Using conceptual knowledge in action and language. In P. Haggard, Y. Rossetti, \& M. Kawato (Eds.), Sensorimotor foundations of higher cognition, attention \& performance $X X$. Oxford, UK: Oxford University Press.

Wolpert, D. M., Doya, K., \& Kowato, M. (2003). A unifying computational framework for motor control and social interaction. In C. Frith \& D. Wolpert (Eds.), The neuroscience of social interaction. Oxford, UK: Oxford University Press.

Wolpert, D. M., Ghahramani, Z., \& Jordan, M. I. (1995). An internal model for sensorimotor integration. Science, 269(5232), 1880-1882.

Wohlschläger, A. and Bekkering, H. (2002). Is human imitation based on a mirror-neuron system? Some behavioural evidence. Experimental Brain Research, 143(3), 335-341. 